A ambigüidade, efeito das estruturas discursivas, gera a possibilidade de várias leituras de um mesmo texto. A produção da leitura totalizanque se prendam a suposições sobre as escolhas do autor.

O termo leitura é sinônimo de isotopia. 2

- Propomos então, conhecer as possibilidades de leituras através LEITURA

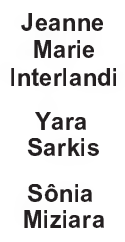

É ao nível das estruturas semióticas que deveremos situar o problema. Um conteúdo pode, por exemplo, ser interpretado simultaneamente como actante-herói, ou como actante anti-herói. Isto porque actantes, unidades das estruturas semióticas profundas, definem-se em relação aos conteúdos investidos. Podemos ter, desta maneira, duas descrições da estrutura profunda do relato, possibilitando duas leituras. Esta ambigüidade surge também na estrutura de superfície onde as funções podem receber interpretações contraditórias.

Não dispomos no momento, de uma teoria de leitura que nos permita descrever com precisão os textos literários. No entanto,osfolcloristas elaboraram técnicas de descrição que permitem o conhecimento coerente das estruturas de seu objeto de estudo. 4

F Rastier propõe uma extensão destas técnicas aos textos literários, o que poderia constituir uma via conveniente para a formação da teoria de leitura. A hipótese de trabalho que o orienta é: a ambigüidade dos textos literários é uma ambigüidade do tipo sintático, uma vez que um mesmo conteúdo pode receber categorizações actanciais contraditórias.

Nos textos monológicos, a existência de um narrador único, não presente como ator do relato, facilita o trabalho da descrição. 
Contrariamente, nos textos dialógicos, a função de narração é assegurada, via de regra, pelos próprios atores do relato. A presença de diversos narradores gera a possibilidade de várias versões do relato. Estas versões ligam-se ao problema do reconhecimento do valor de verdade do relato. A solução disto nos impõe o seguinte procedimento: consideraremos como pertencente à verdade do relato o conteúdo litigioso RECONHECIDO por narradores-actantes opostos.

Por exemplo, em O DELATOR, o Filho pode assumir o papel actancial de traidor, uma vez que o Pai e a Mãe o reconhecem como tal, contudo, este fato não é reconhecido pelo Filho, o que implica no comprometimento de seu valor de verdade. Por outro lado, o Pai nega seu contrato com o Estado. Este fato é reconhecido por todos. Pertence, portanto, à verdade do relato.

\section{Modelo utilizado:}

F. Rastier: Les niveaux d'ambiguité des structures narratives

Texto: O Delator de Bertolt Brecht - tradução feita por alunos da ECAUSP, Curso de Teatro e Curso de Rádio e TV, 1970.

2 - $A$ descrição da estrutura

narrativa
1.1- A estrutura de superfície. Estão compreendidos aqui três níveis hierárquicos: atores e processos, que são constituintes dos enunciados canônicos a partir dos quais se defînem os papéis formais dos atores; funções, estabelecidas após a identificação dos enunciados canônicos; sintagmas narrativos, que compreendem um agrupamento de funções que se pressupõem mutuamente.

Conforme a estrutura dos enunciados canônicos é manifestada pelos enunciados lingüísticos, teremos as diferentes funções e os diferentes papéis formais.

Os enunciados canônicos são engendrados por:

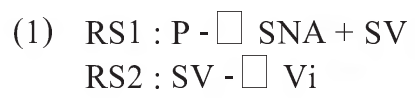

Desta estrutura obteremos a função deslocamento (d), que estabelece 
disjunção espacial/temporal, onde $\mathrm{SNa}$ é o papel formal do agente (G).

(2) $\mathrm{RS} 1: \mathrm{P}-+\quad \mathrm{SNa}+\mathrm{SV}$

$\mathrm{RS} 2: \mathrm{SV}-\square \mathrm{Vtx}+\mathrm{SNb}$

Esta estrutura define o agrupamento de duas funções análogas das quais resulta a função luta $(\mathrm{F})$, onde $\mathrm{SNa}$ : agente VS SNb; objeto, são categorias de papéis formais permutáveis.

(3) $\mathrm{RS} 1: \mathrm{P}->\mathrm{SNa}+\mathrm{SV}$

RS2 : SN - $\square$ Vty $+-\mathrm{SNb}\left(\right.$ sprep $\left.^{\mathrm{c}}\right)$

Define a função comunicação (C) se o processo compreende o sema transmissão; bem como a função contrato (A) obtido pelo agrupamento de mando (m) e aceitação (a):

são articulados pelas categorias: destinador (D1)/ destinatário (D2). Incluímos aïnda a função conseqüência (não c).

1.a— Inventário das funções e dos sintagmas.

As funções são apresentadas na sua ordem de sucessão no tempo do relato e não na ordem de sua manifestação no discurso lingüístico. Algumas funções são supridas, isto é. são pressupostas por outras funções e não manifestadas diretamente no texto, (estão assinaladas entre barras).

As funções não reconhecidas, isto é, aquelas que não pertencem àverdade do relato, são acompanhadas de um ponto de interrogação.

As funções isoladas são incluídas na lista dos sintagmas: pertencem àlista de funções por sua estrutura e àquela do sintagma por ser uma unidade narrativa independente.

Os sintagmas (ou grupo de funções, possuindo um ou mais atores em comum, ligadas por relação de pressuposição) podem ser descontínuos no tempo do relato. A construção desse inventário permite-nos estabelecer algumas versões possíveis do relato. 


\begin{tabular}{|c|c|c|c|}
\hline $\begin{array}{l}\text { número do } \\
\text { * } 1 \mathrm{nt} \text { agma }\end{array}$ & $\mid \begin{array}{c}n \text { « d « } \\
\text { funçàa }\end{array}$ & At ore\#\# 1 in mcesso* & $\begin{array}{l}\text { simboio de } \\
\text { função }\end{array}$ \\
\hline 1 & 1 & $\begin{array}{l}\text { Km inhel crimenl o de cnnt.rfltnentre Estado (DI) e } \\
C 1(1 \ddot{\prime \prime}(1 \text { Aon }(1) 2)\end{array}$ & $1 * 1$ \\
\hline $\overrightarrow{2}$ & 2 & $\begin{array}{l}1 \times 81(01,1) 21 \text { Máe }(1) 1,1) 2 \text { ) ligados BOM Miller } \\
\text { por compromisso de amiraric. (0:objeto virtual) }\end{array}$ & $1 * 1$ \\
\hline \multirow[t]{4}{*}{3} & 3 & $\begin{array}{l}\text { 1*0 ft o Miller } 11>1 \text { t ligados iproc. ntiitil) Ho } k * m \text { In- } \\
\text { do (1)2) por contrato ene o lar. (0. virtual; }\end{array}$ & $|A|$ \\
\hline & 4 & $\begin{array}{l}\text { Hiller (A2) acusado iproc.) num processode ins } \\
\text { peçáo crmco lar (EstadoAl) }\end{array}$ & $\mathrm{F}$ \\
\hline & 5 & $\begin{array}{l}\text { Miller (DI) chama iproc.), Pai (D2) ao telefone. } \\
\text { Pai (DI) se recusa (năoproc.) atender. }\end{array}$ & 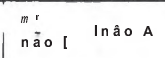 \\
\hline & 6 & $\begin{array}{l}\text { Pai }(01,1) 2) \text { Mäe }(1) 1,02 \text { ) 1 i gados (proc.) porca - } \\
\text { samentolo } 1 \text {. }\end{array}$ & A \\
\hline \multirow[t]{4}{*}{4} & 7 & $\begin{array}{l}\text { Estado (A1) censura (proc.) fala (0:proc, vir } \\
\text { tual) dos individuos (A2) }\end{array}$ & $\mid \mathrm{F} I$ \\
\hline & 8 & Pai (DI) critica impossibilidade de falar (0) & $|A|$ \\
\hline & 9 & $\begin{array}{l}\text { M.ie (01) adverte (proc.) Pai (DI) } \\
\text { Pai (DI) nāoaceita (proc.) dá justificativa } \\
\text { aparente (objetovirtual) }\end{array}$ & nào a L $\operatorname{lnào~A}$ \\
\hline & 10 & $\begin{array}{l}\text { Empregada }(D 1,02) \text {, Paie Mãe }(D 1, D 2) \text { ligados } \\
\text { por um contrato de serviço }\end{array}$ & $|A|$ \\
\hline \multirow[t]{4}{*}{5} & 11 & $\begin{array}{l}\text { Empregada (DI) ligada por relaçăofilial (proc.) } \\
\text { ao chefe de grupo(Da) }\end{array}$ & A \\
\hline & 12 & Empregada $(r$,$) entra$ & d \\
\hline & 13 & Pai ((i) Interrompe (proc.) a fala (obj.) & nāoc c \\
\hline & 14 & Empregada (G) sal (proc.) & d \\
\hline \multirow[t]{8}{*}{6} & 15 & $\begin{array}{l}\text { Pai (1)1,02) e filho (DI, D2) ligados por contra- } \\
\text { to fam i1 i a r }\end{array}$ & $|A|$ \\
\hline & 16 & Kilho (DI) ligado (proc.) à juventude Hitleriana & A \\
\hline & 17 & Pai (DI) năo reconhece & nà o c \\
\hline & 18 & $\begin{array}{l}\text { Kilho (P1, D } 2) \text { Ic (Proc.) jornal (0) por mando } \\
\text { dochefe degrupo (DI) }\end{array}$ & $\cdot I^{*}$ \\
\hline & 19 & Pai (A1) censura iproc.) o fillho (A2) & $\mathrm{F}$ \\
\hline & 20 & $\begin{array}{l}\text { Pai (DI) impóe (proc.) uma ordem (obj. virtual) } \\
\text { Kilho (DI) cumpre (proc.) }\end{array}$ & $\because=$ IA 7 \\
\hline & 21 & $\begin{array}{l}\text { Mãe (DI) manda (proc.) filhosair (obj.virtual) } \\
\text { Filho (DI) nãosai (obj.: processo virtual) }\end{array}$ & nä̀ $=\left\lfloor^{\text {nao }}\right.$ \\
\hline & 22 & Pai (A1) ataca (proc.) jornais (A2) & $r$ \\
\hline \multirow[t]{4}{*}{7} & 23 & $\begin{array}{l}\text { Màe (DI) reconhece iproc.) contrato (obj.)entre } \\
\text {-Jornal Estado. }\end{array}$ & $/ \mathrm{A} /$ \\
\hline & 24 & $\begin{array}{l}\text { Màe (DI) procura justificar (proc.) jornais }(0) \\
\text { Paí (DI) năo aceitou (proc.) justificaçăo }(0)\end{array}$ & $\operatorname{mon}_{\text {não }}^{\text {riào }}$ \\
\hline & 25 & Mãe (DI) pede (proc.) explicaçōes (obj.virtual) & nàoc c \\
\hline & 26 & Pai (Al) ataca (proc.) Palacio do Governo (A2) & $\mathrm{F}$ \\
\hline
\end{tabular}




\begin{tabular}{|c|c|c|c|}
\hline $\begin{array}{l}\text { nÚMro de } \\
\text { aintsgm }\end{array}$ & no da & Atores - Processon & $\begin{array}{l}\text { sínbolo de } \\
\text { função }\end{array}$ \\
\hline & 27 & $\begin{array}{l}\text { Mãe (D1) pede (proc.) rar.öes do nervosisno do } \\
\text { pat (D2). PaI (D1) não oa dá (não proc.) }\end{array}$ & 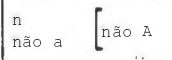 \\
\hline 8 & 28 & $\begin{array}{l}\text { Filho ( } \mathrm{R} \text { aal aea ser percebido (proc, obj. vin } \\
\text { tual) }\end{array}$ & d \\
\hline \multirow[t]{2}{*}{0} & 20 & $\begin{array}{l}\text { Pal (D1) nantee (proc.) ui contrato coe esco- } \\
\text { la e Juventude (D2) }\end{array}$ & $1 * 1$ \\
\hline & 30 & Pai (DI) ignora (proc.) noreas que deve seguir & $/ \mathrm{A} /$ \\
\hline \multirow[t]{4}{*}{10} & 31 & Mãe (G) coeunica (proc.) ausência do filho & c \\
\hline & 32 & $\begin{array}{l}\text { Mãe (A2) desconfia (proc. obj. virtual) do fi- } \\
\text { lho (A1) }\end{array}$ & F 7 \\
\hline & 33 & $\begin{array}{l}\text { Mãe (DI) confirma (proc.) saida do filho lobj. } \\
\text { virtual) }\end{array}$ & c \\
\hline & 34 & $\begin{array}{l}\text { Pai (DI) pede (proc.) explicaçóes pela preocupa } \\
\text { ção (Obj. virtual) } \\
\text { Mãe (DI) as dá (proc.) }\end{array}$ & $\begin{array}{lllll}\text { n } & & {[\text { não }} & \text { A } & 7 \\
\text { a } & 7 & \end{array}$ \\
\hline 11 & 35 & Filho (AI) delata pal (A2) & $/ F / 7$ \\
\hline \multirow[t]{5}{*}{12} & 36 & $\begin{array}{l}\text { - Mãe (D1) adverte (proc.) ao pal (D2) } \\
\text { Pai (D1) não aceita (não proc.) advertência }\end{array}$ & $\begin{array}{lllll}\text { n } 7 & & {[\text { não }} & \text { A } & 7 \\
\text { não a } & & \end{array}$ \\
\hline & 37 & Mãe (AI) procura (proc.) convencer pal (A2) & năo $\mathrm{F} 7$ \\
\hline & 38 & $\begin{array}{l}\text { Pai (D1) não se deixa convencer aparentenente } \\
\text { (năo proc.) }\end{array}$ & não c \\
\hline & 30 & $\begin{array}{l}\text { - Mãe (DI) telefona (proc.) a procura do filho } \\
\text { (obj. virtual) }\end{array}$ & C \\
\hline & 40 & Pal (DI) coneça a vacilar (proc. virtual) & não c \\
\hline \multirow[t]{4}{*}{13} & 41 & $\begin{array}{l}\text { Mãe (A1) acusa o pai (A2) palas acusações ao ES } \\
\text { tado }\end{array}$ & $i_{i}$ \\
\hline & 42 & Pal (năo Al) Inverte f.9, f.22>f.25 & não F \\
\hline & 43 & Pai(D1) duvida da náe (02) & não c \\
\hline & 44 & $\begin{array}{l}\text { Pai (A1) contesta (proc.) nãe (D2) } \\
\text { Măe (02) reage (proc.) coao agredida aparente }\end{array}$ & E 7 \\
\hline \multirow[t]{3}{*}{14} & 43 & $\begin{array}{l}\text { Pai (DI) critlca (proc.) o filho (obj. á nãe (DI) } \\
\text { Măe (DI) năo aveita critica aparentenente } \\
\text { proc.) }\end{array}$ & não a $\left[\begin{array}{lll}\text { năo } & \text { A } 7 \\
& \end{array}\right.$ \\
\hline & 46 & Pal (DI) tene (proc.) forças ameaçadoras & c \\
\hline & 47 & $\begin{array}{l}\text { Pal (01) aceita falsamente (proc.) order im- } \\
\text { posta (obj.) }\end{array}$ & /não Al \\
\hline 13 & 48 & $\begin{array}{l}\text { Măe (D1) propõe (proc. atual) acordo lobj. vir } \\
\text { tual) ao pal (D2) } \\
\text { Pai (D2) não aceita (não proc.) }\end{array}$ & não $[$ não \\
\hline \multirow[t]{4}{*}{16} & 49 & Mãe (D1) procura tranqüilizar (proc.) ○ pal (D2) & C 7 \\
\hline & 50 & $\begin{array}{l}\text { o telefone (D1) chana (proc. atual). Pai e nãe } \\
\text { (D2) năo respondern (não proc.) }\end{array}$ & nào a $[$ não $\mathrm{A}$ \\
\hline & 51 & $\begin{array}{l}\text { Pai (AI) acusa (proc.) o filho (A2) de traição } \\
\text { (ob. virtual) }\end{array}$ & F \\
\hline & 32 & Mãe (D1) adverte (proc.) ao pai (D2) & c \\
\hline
\end{tabular}




\begin{tabular}{|c|c|c|c|}
\hline $\begin{array}{l}\text { número do } \\
\text { sintagra }\end{array}$ & $\begin{array}{l}\mathrm{n}<? \text { da } \\
\text { funçăo }\end{array}$ & Atores e Processos & $\begin{array}{l}\text { sínbolo de } \\
\text { função }\end{array}$ \\
\hline \multirow[t]{3}{*}{17} & 53 & $\begin{array}{l}\text { Pai (D1) pede a crus (obj.) a «ăe (02) } \\
\text { Mãe (01) traz (proc.) }\end{array}$ & $\square[*$ \\
\hline & 54 & $\begin{array}{l}\text { Pai (DI) ouve (proc.) barulho da porta (0) e diz } \\
\text { mãa (D2) }\end{array}$ & c \\
\hline & 55 & $\begin{array}{l}\text { Pai emãe (DI) sen te* (proc.) a aneaça lobj.) pró - } \\
\text { x i ra }\end{array}$ & não . ? \\
\hline \multirow[t]{4}{*}{18} & 56 & Filho (G) volta (proc.) & d \\
\hline & 57 & $\begin{array}{l}\text { Pai (DI) pede (proc. atual) explicaçăo (obj.) } \\
\text { virtual) ao filho (02) } \\
\text { Filho(DI) as dá (proc. atual) }\end{array}$ & a $[A$ \\
\hline & 58 & $\begin{array}{l}\text { Mãe (D1) faz perguntas (proc. atual) ao filhd } \\
\text { (D2) } \\
\text { Filho (D1) responde (proc. atual) }\end{array}$ & a 7 A ? \\
\hline & 59 & $\begin{array}{l}\text { Pai (DI) coloca (proc.) dúvida (obj.) mãe (D2) } \\
\text { não aceita nern nega (obj. proc. virtual) }\end{array}$ & :» *7 \\
\hline
\end{tabular}

\section{1.b- As ambigüidades da estrutura superficial do relato}

Operando sobre o inventário das funções podemos chegar a um primeiro nível de conclusões. A ambigüidade da estrutura superficial se constrói a partir das funções 9, 18, 29, 32, 33, 34, 38, 41, 42, 46, 48, 54,58 não pertencentes à verdade do relato. Com isto constatamos que, um mesmo enunciado lingüístico pode manifestar duas estruturas narrativas superficiais diferentes. É este o primeiro nível de ambigüidade, situado como vimos, nas estruturas de superfície.

A primeira versão, comporta um número relevante de funções (42) cuja verdade é reconhecida. Assim, Mãe e Filho definem-se pelo reconhecimento de um contrato familiar com o Pai. Esta versão é a única incontestável se nos prendermos apenas às funções que nos permitam constatar o funcionamento metalinguístico do texto.

A segunda versão, apoiada nas funções não reconhecidas é contestável uma vez que agrupa apenas 13 funções Neste caso, somos forçados a reconhecer que Mãe e Filho, assumem o contrato estatal, opondo-se ao Pai.

1.2- Estrutura formal profunda

Consideremos o inventário dos sintagmas à procura de suas regu- 
laridades. Derivam estas, da identidade ou analogia entre atores e funções, o que nos permite proceder à homologação dos sintagmas. O resultado de tal operação é o inventário das seqüências paradigmáticas, o qual obedece uma ordem de pressuposição mais ou menos similar à cronologia do relato.

\begin{tabular}{|c|c|c|c|c|}
\hline $\begin{array}{l}\text { Sequênc U } \\
\text { I }\end{array}$ & $\begin{array}{l}\text { A ligada a } B, M \\
\text { por us contrato } \\
\text { prsanchido fal- } \\
\text { aasente por } \mathrm{B} \text { e } \\
\text { M }\end{array}$ & $\begin{array}{l}\text { A roapa contrato } \\
\cos \mathrm{M}\end{array}$ & M raa a B & 8 recues $x$ \\
\hline $\begin{array}{l}\text { A Estado } \\
\text { B Pai } \\
\text { C Mi } 11 \text { or } \\
\end{array}$ & f. $3,22,26$ & f. 4 & E. 5 & f. 5 \\
\hline $\begin{array}{l}\text { Sequênc ia } \\
\text { II }\end{array}$ & $\begin{array}{l}\text { A e C ligados } \\
\text { por un contrato } \\
\text { reconhecido por } \\
\mathrm{A} \text { e C }\end{array}$ & $\begin{array}{l}\text { B não reconhece } \\
\text { contrato entre } \\
\text { A E C }\end{array}$ & $\begin{array}{l}\text { B isputa ua } \\
\text { outro contra } \\
\text { to a } C\end{array}$ & \\
\hline $\begin{array}{l}\text { A Estado } \\
\text { B Pai } \\
\text { C Filho }\end{array}$ & f. 16,18 & f. 16,17 & f. 21 & \\
\hline $\begin{array}{l}\text { A Estado } \\
\text { B Pai } \\
\text { C Juventude }\end{array}$ & f. 1,30 & f. 1 & f. 17 & \\
\hline $\begin{array}{l}\text { A Estado } \\
\text { B Pai } \\
\text { C Filho }\end{array}$ & f. $23,23,18$ & f. 18 & f. 22 & \\
\hline $\begin{array}{l}\text { A Estado } \\
\text { B Pai } \\
\text { C Eapregada }\end{array}$ & f. 11,13 & f. 10 & f. 13 & \\
\hline $\begin{array}{l}\text { Nequenc Ia } \\
\text { III }\end{array}$ & $\begin{array}{l}\text { B a C ligados } \\
\text { por ua contrato } \\
\text { reconhecido por } \\
\text { aabos. }\end{array}$ & $\begin{array}{l}\text { A e C ligadoa } \\
\text { por ua contrato } \\
\text { não reconhecido } \\
\text { por B }\end{array}$ & Dadverte $n$ & B taaa C \\
\hline $\begin{array}{l}\text { A Kmtudo } \\
\text { B Pai } \\
\text { C Filho } \\
\text { D Măe } \\
\end{array}$ & f. 13 & f. 16,1 & f. 33 & f. 48 \\
\hline $\begin{array}{l}\text { A Estado } \\
\text { B Pai } \\
\text { C Eapregada } \\
\text { D Mãe } \\
\end{array}$ & f. 10 & f. 11,13 & f. 40 & f. 13 \\
\hline $\begin{array}{l}\text { A Estado } \\
\text { B Pai } \\
\text { C Escola } \\
0 \text { Mãe } \\
\end{array}$ & f. 28 & f. 19,29 & f. 40 & f. 29 \\
\hline $\begin{array}{c}\text { Sequênc ia } \\
\text { IV }\end{array}$ & $\begin{array}{l}\text { D suapeita que G } \\
\text { preenche falsa } \\
\text { aente contrato } \\
\text { coa B e D }\end{array}$ & G sai & $D$ adverte $B$ & B tsae \\
\hline $\begin{array}{l}\text { B Pai } \\
\text { D Măe } \\
\text { G Filho } \\
\end{array}$ & f. 28,32 & f. 28 & f. 33,38 & f. 39 \\
\hline $\begin{array}{c}\text { Sequênc ia } \\
\mathrm{V}\end{array}$ & $\begin{array}{l}\text { D reconhece con } \\
\text { trato entre } \mathrm{A}^{-} \\
\mathrm{C}\end{array}$ & $\begin{array}{l}\text { D procura conven } \\
\text { cer } \mathrm{B}\end{array}$ & $\begin{array}{l}\text { B se deixa } \\
\text { convencer }\end{array}$ & \\
\hline $\begin{array}{l}\text { A Estado } \\
\text { B Pai } \\
\text { C Filho } \\
\text { D Mãe } \\
\end{array}$ & f. 38 & f. 35 & f. 39 & \\
\hline $\begin{array}{l}\text { A Estado } \\
\text { B Pai } \\
\text { C = Jornal } \\
\text { D } 3 \text { Măe }\end{array}$ & f. 23 & f. 24 & f. 42 & \\
\hline
\end{tabular}




\begin{tabular}{|c|c|c|c|c|}
\hline Seqüência VI & $\begin{array}{l}\text { B e D ligados por us } \\
\text { contrato reconhecido } \\
\text { por anbos }\end{array}$ & $\begin{array}{l}\text { D reconhece } \\
\text { contrato en } \\
\text { tre } A \text { E }\end{array}$ & $\begin{array}{l}\text { D procura con- } \\
\text { vencer B }\end{array}$ & $\begin{array}{l}\text { B reconhe } \\
\text { ce contra } \\
\text { to } \cos \mathrm{A}\end{array}$ \\
\hline $\begin{array}{l}\text { A } \gg \text { Estado } \\
\text { B Pai } \\
\text { C. Mãe }\end{array}$ & f. 6 & f. 41,48 & f. 49,51 & f. 53 \\
\hline Seqüencia VII & $\begin{array}{l}\mathrm{B} \text { reconhece contrato } \\
\text { entre } \mathrm{A} \in 0\end{array}$ & G volta & $\begin{array}{l}G \text { responde per } \\
\text { guntas a } B \text { e } D\end{array}$ & $\begin{array}{l}B \in D \\
\text { teses }\end{array}$ \\
\hline $\begin{array}{l}\text { A Estado } \\
\text { B Pa } 1 \\
\text { C Mãe } \\
\text { D Filho }\end{array}$ & f. 43 & f. 56 & f. 57,58 & f. 46,59 \\
\hline
\end{tabular}

o inventário das seqüências nos permite dois modos de abordagem:

a) no plano paradigmático, construindo através da homologação dos atores, os actantes;

b) no plano sintagmático, relacionando as seqüências.

primeiro.

Destes dois modos de operar sobre as seqüências, reteremos o

\section{Construção dos actantes}

A partir do conteúdo funcional assumido pelo ator é que se definem os papeis formais. O agrupamento de papéis formais compatíveis é o que chamaremos de actante.

\begin{tabular}{|c|c|c|c|}
\hline $\begin{array}{l}\text { Grupo de } \mathrm{Pa}- \\
\text { peis }\end{array}$ & Papeis & $\begin{array}{l}\text { sísh. de fun- } \\
\text { çôs }\end{array}$ & sequênc ias \\
\hline \multirow[t]{3}{*}{ Grupo A } & $\begin{array}{l}\text { al: contrato } \\
\text { (santes contrato } \cos \mathrm{C})\end{array}$ & (A) & II, ${ }_{\mathrm{V}} \mathrm{III}$ \\
\hline & $\begin{array}{l}\text { a2: rosplnento de contrato } \\
(\cos \mathrm{M})\end{array}$ & $($ (ñ̃o $A)$ & 11 \\
\hline & 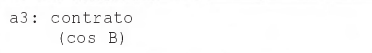 & (A) & $\mathrm{VI}$ \\
\hline \multirow[t]{5}{*}{ Grupo B-- } & $\begin{array}{l}\text { b1: não reconhecisento de contrato } \\
(\cos A)\end{array}$ & $($ não A $)$ & I \\
\hline & $\begin{array}{l}\text { b2: não reconhecisento de contrato } \\
\text { (entre A C) }\end{array}$ & (não A) & II, III \\
\hline & $\begin{array}{l}\text { b3: isputa contrato } \\
\left(\begin{array}{c}\text { a c }) \\
\text { (n) }\end{array}\right.\end{array}$ & (s) & II \\
\hline & b4: tese & (A) & III, IV,VII \\
\hline & b5: recusa contrato $(\cos \mathrm{M})$ & $($ não A $)$ & I \\
\hline
\end{tabular}




\begin{tabular}{|c|c|c|c|}
\hline $\begin{array}{l}\text { Grupo do Ps- } \\
\text { pou }\end{array}$ & Papeis & $\begin{array}{l}\text { siabolo do fun- } \\
\text { çấes }\end{array}$ & aequénc toa \\
\hline & b6: contrito (co. c) & (A) & III \\
\hline & b7: reconhecisento do contrito & IA) & $\mathrm{VI}$ \\
\hline \multirow[t]{3}{*}{ Grupo $\mathrm{C}<$} & cli contrito (coa A) & (A) & II, III \\
\hline & $\begin{array}{l}\text { c2: preenche falmamente contrato } \\
(\operatorname{coa} B)\end{array}$ & $(\mathrm{nã} \circ \mathrm{A})$ & III \\
\hline & 03 : contrito (coa B) & (A) & II I \\
\hline \multirow[t]{6}{*}{ Grupo $D^{*}$} & $d I$ : suspeito (da G) & $(\mathbb{F})$ & IV \\
\hline & $d 2$ : tese & $($ năo c) & VII \\
\hline & d3: tento convencer (B) & $($ não c) & $I I I, I V, V, V I$ \\
\hline & d4: contrato (coa B) & (A) & $\mathrm{vI}$ \\
\hline & $\begin{array}{l}\text { d5: reconheclaento de contrato } \\
\text { (entre A B) }\end{array}$ & (a) & vI \\
\hline & dfi: for adrertências (a R) & $($ não c) & III, IV \\
\hline \multirow[t]{2}{*}{ Grupo G. } & glt sal & (d) & IV \\
\hline & g2: responde perguntas (a $B$ D) & (C) & VII \\
\hline
\end{tabular}

Cada classe de atores(agrupasento de papeis fornais) corresponda us ac tante.

\begin{tabular}{|c|c|c|}
\hline Actante & Pape is & Atores \\
\hline 1: & $\begin{array}{l}\text { A } \\
\text { a1, a2, a3 }\end{array}$ & Estado \\
\hline 2: & $\begin{array}{l}\text { B } \\
b 1, b 2, b 3, b 4, b 5, b 6, b 7,\end{array}$ & $\mathrm{Pai}$ \\
\hline 3: & 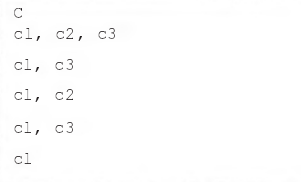 & $\begin{array}{l}\text { Filho } \\
\text { Juventude } \\
\text { Escola } \\
\text { Eapregada } \\
\text { Jornal }\end{array}$ \\
\hline 4: & $\begin{array}{l}D \\
d 1\end{array}, d 2, d 3, d 4, d 5, d 6$, & мäe \\
\hline 5: ’ C - & GI, Oy (), (1, (t & Filho \\
\hline
\end{tabular}

Os actantes têa ralências funcionais diferentes, É a coabinatória dos gru pos de papais que nosperaitirá foraular interpretação do relato.

Consideramos relato o algoritmo ou série dialética de operações sobre conteúdos. Conhecendo as propriedades formais dessas operações aproximamo-nos do sentido do relato.

Trabalhamos em duas direções: 
a) descreverdo os sistemas de conteúdos que são investidos no relato;

b) mostrando as correlações estabelecidas entre a estrutura semántica (sistema de operações formais) e o sistema semiológico (os conteúdos investidos).

\section{A estrutura elementar dos sistemas de conteúdos investidos}

A estrutura binária, elementar, da significação, articula cada sistema semiótico em dois espaços disjuntivos, ou deixis, que podem ser conotados pelas categorias euforia vs disforia. Por exemplo, todo o sistema semiológico das mitologias indígenas da cozinha, articula-se conforme a oposição: cozido (cultural, eufórico) vs cru (natural, disfórico).

\section{Actantes e conteúdos investidos:}

Um actante é definido pelo grupo de papéis formais que assume, e também pelos conteúdos que lhe são atribuidos.

Nós podemos, então, classificar os actantes pelo lugar que os conteúdos, ai investidos, ocupam no sistema semiológico imánente ao relato. A realização de tal classificação se justifica porque não podemos postular universos formais que permitam identificar nas suas modalidades os atos do herói, do traidor; não é também possível falarmos em universos substanciais, porque não podemos a priori atribuir qualificações aos actantes.

Chamamos sujeito - herói, uma manifestação da deixis positiva; traidor ou anti-sujeito,a uma manifestação da deixis negativa, trata-se de definições negativas de deixis correspondentes e como é a sua manifestação que torna possível aquela das definições positivas destas mesmas deixis, são estes dois actantes os realizadores das operações de transformação dialética: os actantes adjuvante e oponente são definidos pela relação hipotáxica que mantêm em relação ao herói e ao traidor, respectivamente.

No relato - O Delator - nós verificamos que os grupos de papéis definem por suas compatibilidades, dois espaços funcionais separados: o grupo de papéis que define o Pai vs todos os outros. Podemos supor que esta divisão é correlata à divisão do sistema de conteúdos investidos nas duas deixis. 
Observamos que durante quase todo o desenrolar do relato há luta entre a.2 (que assegura o grupo de papéis do Pai) de um lado, e os outros actantes que asseguram os outros papéis, de outro lado. É esta luta que coloca em relação dialética as duas deixis, porisso permite manifestar a inversão dos conteúdos.

No texto, as qualificações dos actantes aparecem sob as formas de determinações, denominações e definições. Como não temos aqui um narrador único, as qualificações de um mesmo narrador-actante podem diferir conforme sejam ou não assumidas, isto é, reconhecidas e designadas no discurso como anafóricas de $e u$.

A deixis positiva:

4-0 sistema

de valores

sociais

medida do possível por meio dos lexemas do texto, podemos realizar o inventário dos conteúdos assumidos pelos actantes em relação de oposição ao actante a.2 (o Pai).

a.3- Filho-sentimentos nacionalistas

acata as ordens do chefe de grupo

pertencente à juventude hitlerista

Empregada- filha do chefe de grupo

Jornal- publica inquérito contra os padres.

(A Igreja não está vinculada ao Estado).

Juventude - Hitler lhe atribui a responsabilidade pela Alemanha do Futuro.

Escola- Não explicita suas determinações.

a. 5-Empregada- Silencio.

Filho- Silêncio (-não abre a boca, fala pouco).

a.1- O Poder- este actante assume a característica de totalidade: é o responsável pelas motivações dos outros actantes, e apresentado como o instaurador do jogo narrativo onde ele toma lugar e é ao mesmo tempo a condição de existência do sistema imanente às qualidades manifestadas, incluindo as suas próprias. Nesta última consideração é o metasujeito do sistema de valores sociais.

O Poder é definido em relação às normas mencionadas acima: qualifi- 
cativamente lhes é solidário.

a.4- a Mãe- não há discordância nos jornais, todos dizem a mesma coisa a moralização não é ruim

é preciso cuidar da higiene moral do povo reconhece as recomendações de Hitler (Poder) usa o dinheiro como poder de corrupção.

A análise sé mica do inventário e das ocorrências definitórias que o acompanham evidencia urna fîgura nuclear que pode ser considerada como normatividade. Esta fĩgura nuclear funda uma classe semiológica pois é comum a todos os ítens, apresentando-se tanto em enunciados que indicam:

1 - o respeito a uma norma:

respeito a urna norma contratual com a Nação: sentimentos nacionalistas;

respeito a uma ordem contratual com o Poder: acatamento das ordens;

respeito a uma norma do jornalismo: não há discordância nos jornais.

2 - ou simplesmente:

moralização: norma moral de comportamento

silêncio: norma de comportamento

higiene moral: norma de comportamento

família: norma de organização social

corrupção: suborno, norma institucional.

O Poder é o elemento totalitário e abrangente de todo o sistema estabelecido. Define-se de duas maneiras:

1) funcionalmente - é reconhecido como instaurador ou restaurador das normas: mantêm-nas punindo sua transgressão.

2) qualificativamente - é solidário às normas: a transgressão ou denegação das normas é uma transgressão ou denegação do Poder.

Estas normas correspondem aos valores sociais: são códigos comuns, ou códigos contratuais, definidores de uma história. 
Todos estes conteúdos são assumidos, constituindo assim a deixis positiva do sistema.

\section{A deixis negativa}

Os conteúdos não assumidos pelos actantes apresentados acima qualificam, consequentemente, o actante Pai. São obtidos pela negação dos itens da deixis positiva, constituindo a deixis negativa.

\section{Teremos:}

Pai _ quer instaurar sua própria autoridadedentro de casa

- não reconhece a autoridade do chefe de grupo

- não reconhece a norma contratual imposta pelo poder

- não reconhece as normas da comunicação: fala alto, espera que os jornais informem

- não reconhece as normas de moralização e de higiene moral

Miller - não reconhece as normas contratuais.

Valor particular: individualidade.

Nitidamente podemos observar que a figura nuclear que constitui este inventário em classe semiológica é a transgressão de uma norma.

Os conteúdos da deixis negativa e os da deixis positiva são 5 - A estrutura do sistema ordenados por uma relação de implicação.

Na deixis positiva temos uma implicação entre as características das normas gerais de comportamento e o silêncio; na deixis negativa, a transgressão da norma implica num falar. A validade dessa inferência está bem clara no texto.

O silêncio e o falar são as definições negativas das deixis, os reconhecimentos ou não reconhecimentos das normas instauradas pelo sistema são as defmições positivas das deixis.

Podemos então formular um modelo do sistema de valores sociais da seguinte maneira: 

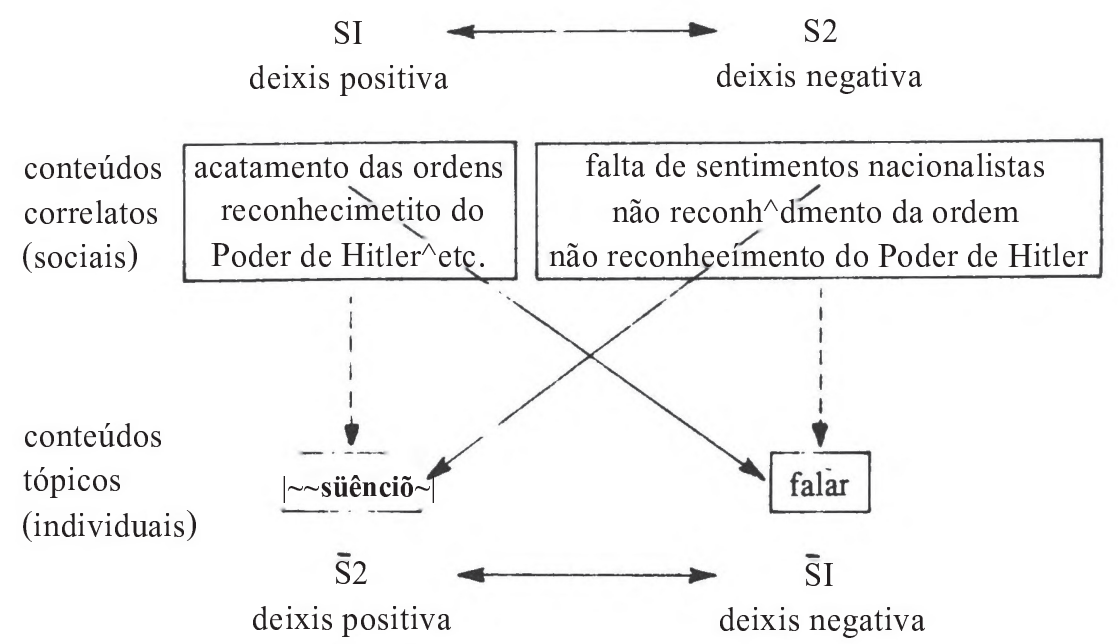

Os conteúdos correlatos e os conteúdos tópicos definem duas isotopias diferentes: a dos valores sociais e aquela dos valores individuais.

Ora, a manifestação dos conteúdos correlatos (definições positivas das deixis) pressupõe a dos conteúdos tópicos (definições negativas das deixis), mas, é ao nível da isotopía dos valores sociais que se desenvolvem as provas operando a inversão dos conteúdos.

6 Interpretação dialética dos actantes e das seqüências
1)

Os actantes: herói e traidor devem caracterizar-s̄e por S2

e $\overline{S 1}$, respectivamente.

a.2 - é o traidor, pois the são atribuídos os conteúdos da deixis negativa, (Pai. Miller). Sua fórmula semiológica é S1 + S2. É preciso negar estes conteúdos para suprimir a alienação.

Duas manifestações desta operação dialética são aqui possíveis: no plano não figurativo, o reconhecimento (que equivale à asserção correlativa - S1 + \$2), no plano figurativo, o não falar.

a.3- é o herói, pois, assume os conteúdos da deixis positiva. Sua fórmula semiológica $(\overline{\mathrm{S}} 2+\mathrm{S}$ ) é exatamente o contrário da fórmula do traidor.

a.4 tem a mesma estrutura semiológica apresentada pelo herói, mas os conteúdos que assume são opostos aos conteúdos que se obtém $t$ lauslormando as suas funções em qualificações, por outro lado, ajuda ao oponente 
(o traidor, seu marido), sobre o plano das funções somente, pois as motivações que assume são contrárias, pode-se assegurar então que, seus conteúdos são hipotáxicos àqueles do traidor. A contradição entre suas motivações e suas funções torna-o um falso herói e um falso oponente. S2 (funções).

Sua estrutura semiológica é, $(\mathrm{SI}+\S 2$ (motivações $)+\left(5>1{ }^{`}+\right.$

a.5- assume o conteúdo S2, é então suscetível de ser herói, mas, na realidade não luta contra o traidor, apenas lhe recusa a aceitação do contrato (a empregada: o contrato de fidelidade, o filho: o contrato de obediência filial acima da obediência ao Poder), É o herói não ativo.

a.1 - subentende todos os conteúdos do modelo. Sua fórmula semiológica é (SI $+\overline{\mathrm{S} 2}+\overline{\mathrm{ST}}+\mathrm{S} 2$ ), é vítima do traidor (suas ações lhe são ofensivas) é ao mesmo tempo o mandador do herói e oponente, pois acolhe também o traidor. É um metasujeito.

Os actantes definidos por um só grupo de papéis têm uma estrutura semiológica simples, aqueles definidos por vários grupos de papéis, têm uma estrutura semiológica mais complexa.

2) Para dar a interpretação dialética de uma seqüência, conhecendo a estrutura semiológica de seus actantes,será preciso:

1 - Determinar a função principal da seqüência, quer dizer, aquela que é implicada pelas outras funções.

2 - Transcrever dialeticamente esta função, sabendo-se que a luta eqüivale à asserção dos conteúdos atribuídos àquele que vence, correlativa à denegação dos conteúdos atribuídos àquele que perde. (No nosso caso existe um conflito verbal, que nós configuramos como luta).

3 - Saber que o contrato eqüivale à possibilidade de asserção dos conteúdos atribuídos ao objeto do contrato.

4 - Saber que a comunicação de um objeto eqüivale à asśerção dos conteúdos atribuídos ao objeto e ao destinador. 


\begin{tabular}{|c|c|c|c|}
\hline $\begin{array}{l}\text { No } \mathrm{d}^{\star} \\
\text { sequênc It }\end{array}$ & conteúdo d* seqüência & $\begin{array}{l}\text { sirnbolo } \\
\text { de funçăo }\end{array}$ & Fórmula dialét ica \\
\hline I & Recusa de contreto pelo traidor, & năo * & $\begin{array}{l}1-\sim \square \mathrm{m} 1 \\
2-\square \quad i 1 \mathrm{~m} 2\end{array}$ \\
\hline 11 & $\begin{array}{l}\text { Não reconhecisento do contratoa aoclala } \\
\text { pel otraidor }{ }^{2} \text { decepçăo do heról^. }\end{array}$ & não A & 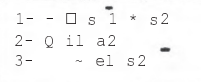 \\
\hline III & $\begin{array}{l}\text { Falsa execução de contrato sociali pelo } \\
\text { traidor }\end{array}$ & A & 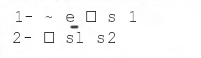 \\
\hline IV & $\begin{array}{l}\text { Conunicação de ura suspeita aó traidor } \\
\text { pelo herói náo-ativol }\end{array}$ & c & $\begin{array}{l}1--\approx a 1 \cdot i^{2} \\
2-\square \operatorname{sic} s 2 \\
3-\square \text { si s2 }\end{array}$ \\
\hline $\mathrm{v}$ & $\begin{array}{l}\text { O herol nao-attvo convence ao traidor } \\
\text { que reconhece contratos entre heróis e o } \\
\text { metasujeito }\end{array}$ & C & $\begin{array}{l}1-\sim \sim \text { el_* } 02 \\
2-\square s 1 s \overline{2} \\
3-e \cos s 2- \\
4-\square \operatorname{sis} 2 . s 1 . s 2\end{array}$ \\
\hline vI & $\begin{array}{l}\text { Confirmação do contrato social }{ }^{1} \text { entre } 0 \\
\text { traidor e metasujeito^ }\end{array}$ & A & 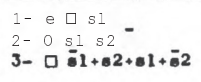 \\
\hline VII & Herói provoca suspeita no traidor & $r$ & $1-\sim \overline{s 1} \mathrm{~s}^{-}$ \\
\hline
\end{tabular}

Símbolos:

= asserção dos conteúdos atribuídos ao vencedor.

= negação dos conteúdos atribuídos ao vencido.

$=\mathrm{o}$ contrato, a aparição da possibilidade de asserção de conteúdos atribuídos ao objeto do contrato.

Alguns problemas surgidos no texto não são resolvidos: por exemplo a contradição entre a Mãe e o sistema (Poder), é aparente, uma vez que seus termos não são os mesmos, pois, as motivações são opostas às funções. O metasujeito, Poder, tem por definição uma estrutura contraditória porque subentende o sistema inteiro, mas suas funções não são contraditórias, tudo se passa como se ele propiciasse os meios utilizados pelo Pai. para realizar a inversão de conteúdos: reconhecendo-o (conforme lhe é proposto através da mãe) ou mandando o filho, ou a empregada, quase impondolhe o siféncio por tais presenças.

A interpretação apresenta muitas lacunas: como situar, digamos, o problema da corrupção? Por outro lado, algumas sequiências comportam operações dialéticas contraditórias, pois afirmam simultaneamente conteúdos situados em deixis diferentes.

Se a interpretação apresenta lacunas é, sem dúvida, porque o 
sistema de valores sociais não é perfeitamente válido. Alguns conteúdos não podem ser aí situados coerentemente: a sinceridade ou não sinceridade do Filho em relação às expectativas do Pai, por exemplo.

Precisamos então, tentar explorar mais extensivamente a base estrutural construída, o que podemos fazer através da introdução do sistema de valores individuais.

A construção deste sistema se fundamenta na procura de uma 8-0 sistema de interpretação dos conteúdos da fala atribuída ao Pai.

valores individuais

\section{Constituição do modelo}

Verificando os conteúdos assumidos pelo Pai, teremos:

crê na autoridade natural, paternal

racionalidade

afirmação da individualidade

amor à humanidade, manifestado no desejo de solidariedade aos

padres

crê nas honrarias tradicionais, o que se evidencia quando busca a

Cruz de Ferro

crê na liberdade

crê na sinceridade do filho e da empregada

repugna-lhe a falsa, moralização, enquanto crê na verdadeira

moralização.

A figura nuclear, fundadora desta classe, a manifestação da natureza, aparece sob diferentes isotopias:

alética: a sinceridade

intelectual: a razão (definida como manifestação da natureza do espírito humano)

psicológica: amor à humanidade.

As demais parecem recobrir também a figura normatividade, com o efeito de sentido funcional: instauração de uma norma própria (afirmação da individualidade, normas de honrarias etc.). 
Tais conteúdos compõem a deixis positiva do sistema, os que lhe são opostos, pertencem à deixis negativa.

Podemos articular os dois inventários da seguinte maneira:

PI

deixis positiva
P2

deixis negativa

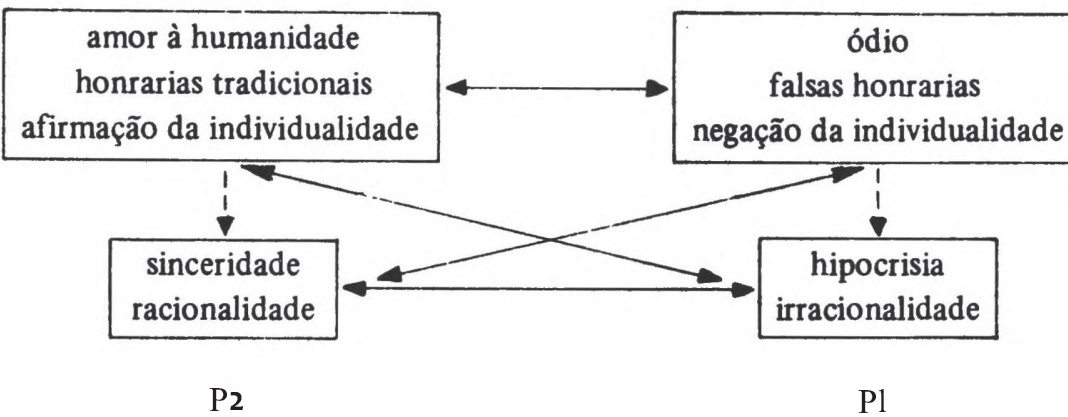

9 - Interpretação dialética dos actantes e das seqüências
1 - Actantes:

a.2- é agora herói, pois, os conteúdos da deixis positiva lhe são atribuídos. Sua fórmula semiológica no começo do relato é: $\mathrm{pl}+\overline{\mathrm{p}} 2$. Do ponto de vista tipológico, difere do herói da interpretação precedente: não restabelece uma ordem em proveito dos mandantes, como o fazia o herói no sistema social; a sua não alienação em relação àquele sistema, implica no cumprimento do contrato enquanto que a alienação implica na livre escolha, de valores na busca de si mesmo, para realizar sua natureza.

a. 5- é traidor, pois, os conteúdos da deixis negativa lhe são atribuídos. A sua fórmula semiológica é:- pl + p2 contrária à do herói. A hipocrisia é um conteúdo que lhe é atribuído. As suas funções pertencem à realidade do relato, mas, não suas motivações, pois os conteúdos que assume não são reconhecidos.

a.3- é também traidor ou anti-sujeito, mas sua fórmula semiológica é diferente pois assume também P2. 
a.4- é adjuvante sobre o plano das funções, mas, é também traidor porque lhe são atribuídos os mesmos conteúdos do traidor, PI e P2 (hipocrisia, negação da individualidade.)

a.1- não existe nesta interpretação. Não é reconhecido, nem necessário, pode existir enquanto desejo. Este desejo não está explícito no discurso, mas, podemos supô-lo através das referências constantemente feitas a um antes, que poderia representá-lo.

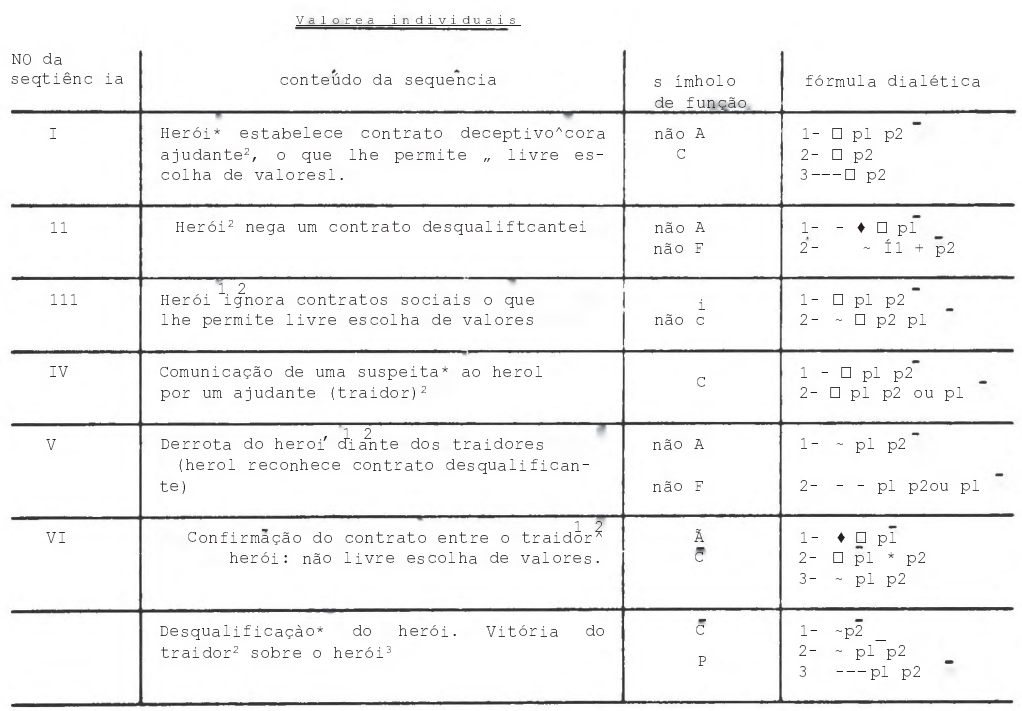

2)

Da mesma maneira que o traidor deixa de ser traidor (seq. VI) e passa a (integrar) os valores instituídos pelo sistema social, inversamente, no sistema de valores individuais, temos:

na primeira fase da seqüência dialética o herói integra a deixis positiva, manifestando livre escolha de valores,

na segunda fase da seqüência, há um deslocamento do herói da deixis positiva para a deixis negativa. Verificamos nesta passagem em que são assumidos os conteúdos da deixis negativa, o processo da alienação. 


\section{JO - Comparação} entre as duas interpretações

\section{1 - Estabelecimento das correlações entre os dois sistemas semiológicos}

Ao nível da estrutura profunda podemos destacar: na segunda interpretação não está presente o metasujeito; traidores e heróis, adjuvantes e oponentes, permutam respectivamente; a Mãe, aqui, se torna não-contraditória; a inexistência do mando e da qualificação dos traidores na segunda interpretação anulam certas diferenciações entre os actantes, a oposição totalitarismo vs individualismo não é pertinente.

\section{Ao nível dialético:}

No primeiro caso Sistema de valores sociais passamos da alienação à adesão ao sistema de valores,no segundo caso,Sistema de valores individuais, da livre escolha de valores à alienação. O sentido do relato é invertido. No entanto, a comparação detalhada das séries dialéticas não é ainda possível, pois necessitamos maior aprofundamento teórico. Não podemos afirmar, a priori, que os cálculos dialéticos que permitiram produzí-las obedeçam exatamente às mesmas regras.

Podemos estabelecer um modelo tridimensional, supondo as seguintes implicações:

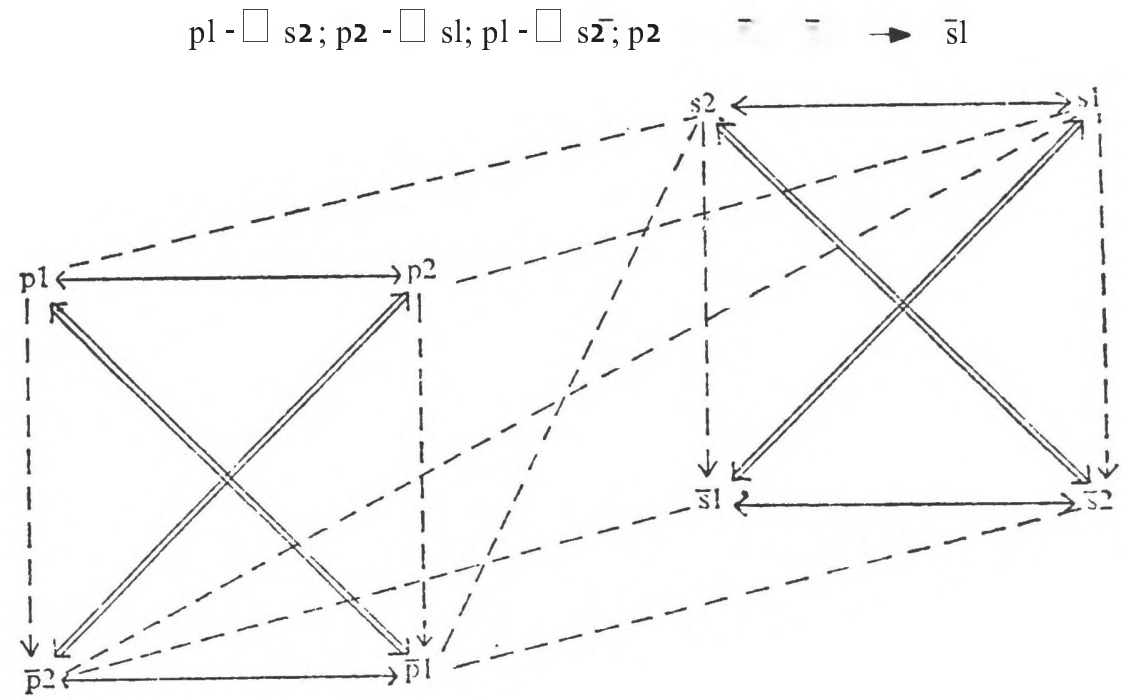

Uma deixis de um sistema pode ser comparada à deixis oposta do outro sistema, ou, as relações excluídas num sistema correspondem às relações admitidas no outro. 
Ao nível dos sememas podemos formular as seguintes correia* ções:

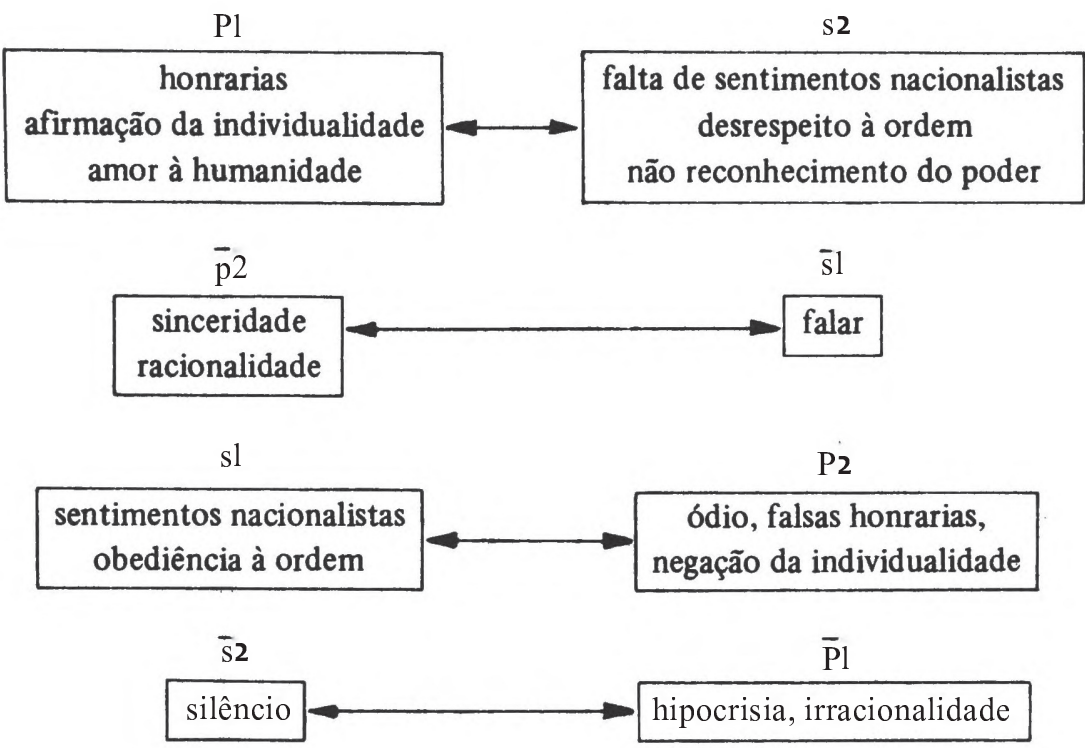

Observações: As categorias sociedade vs indivíduo que não pertencem à metalinguagem semiótica, pertencem ao universo semântico descrito.

É preciso agora formular o estatuto lógico destas correlações ao nível dos semas ou figuras nucleares constitutivas das classes semiológicas.

Designando por P e S as deixis de cada sistema podemos ter:

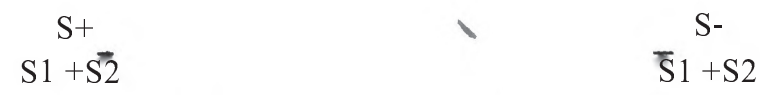

$\stackrel{\text { j-espeito a uma norma } \sim j^{-}}{ } \leftrightarrow$ transgressão de uma norma NI $\mathrm{N} 2$

$\mathrm{P}-(\mathrm{pl}+\mathrm{p} 2)$ $\mathrm{P}+(\overline{\mathrm{pl}}+\mathrm{P} \overline{2})$

$\mathrm{N} 1:$ instauração de uma norma $\longrightarrow$ ausência de norma: N2

não manifestação da natureza (negação do ser): (ē) 
Distinguimos aquí dois eixos semânticos:

a) eixo da normatividade: seus semas estão sempre presentes, combinados a conteúdos funcionais (reconhecimento/ não reconhecimento ou respeito/ transgressão) e/ou aspectuais (instauração: incoativo/ respeito: durativo/ transgressão: terminativo).

b) O eixo da expressividade comporta dois semas: J / e homólogos respectivamente a NI / N2.

A superposição dos dois sistemas semiológicos constitui o modelo de interpretação totalizante.

Transposições de um sistema a outro: $\quad$ como os doissistemas são binários, os conteúdos de uma interpretação podem ser formulados na outra. Assim, os que estão na deixis positiva de um dos sistemas (social), são descritos como assunção da deixis negativa do outro (individual). Seja S 4- - P- e inversamente, seja P+ = S-.

12 - Conclusões provisórias
O texto da peça manifesta duas estruturas narrativas diferentes que, interpretadas através de dois sistemas semiológicos opostos, articulam duas mensagens inversas.

Como avaliar qual é a interpretação mais coerente? Que critérios utilizar? Interessa-nos sobretudo destacar que nenhuma das duas interpretações, tomadas isoladamente, são satisfatórias: a primeira não dá conta das motivações do Pai e a segunda não configura perfeitamente os conteúdos do actante 3 (filho e empregada), para citar apenas alguns exemplos.

É fundamental, portanto, para se obter a leitura totalizante, que realizemos as duas interpretações: uma leitura envia à outra e ambas são essenciais. Mas, concluímos que a descrição aprofundada das estruturas semióticas pode ser sugerida como possível forma de esgotamento do texto e como razoável meio de resolver com propriedade as ambigüidades depreendidas.

A aplicaçã́o do modelo que apresentamos constitui as bases de uma descrição que acreditamos rigorosa.

Julgamo-la particularmente aplicável, como elemento de uma prática 
sistemática, aos textos teatrais, permitindo evitar que espetáculos construídos a partir de leituras incoerentes, parciais ou contraditórias resultem em visível empobrecimento da força criadora daqueles textos.

Entretanto, a solução do problema pensada em toda amplitude é mais complexa do que pode sugerir a aparente simplicidade da aplicação dos conceitos estruturais tal como a realizamos.

As teorias relacionadas com os problemas de leitura, dependem das teorias do texto, as quais estão em plena formação, o que torna impossível colocar conclusões finais aos trabalhos orientados nesse sentido. Podemos incluir nessa preocupação as contribuições de Janos S. Petófi (Teoria Parcial do Texto. TeSWeST), 6 e Julia Kristeva^ (La révolution du langage poétique) e ainda, o pequeno trabalho de Lucia Vaina-Puscã - La stratégie du dialogue dramatique du point de vue de l'opposition vrai-faux?

1 - Este trabalho é o resultado de um seminário realizado no Curso de Semiologia da Narrativa,ministrado pelo prof. Eduardo P. Canizal, na ECA—USP no segundo semestre de 1973. Representa uma aplicação do modelo utilizado por Rastier sobre o texto Dom Juan de Molière, significando sobretudo a procura de um modelo de leitura totalizante.

2 - Isotopia - segundo Greimas, é um conjunto redundante de categorias semânticas que torna possfvel a leitura uniforme da narrativa, tal como ela resulta das leituras parciais dos enunciados após a resolução das suas ambigüidades, a qual é gerada pela própria leitura única. A.J. Greimas. Sémantique Structurale ed. Langue et Langage - Larousse, Paris, 1966.

3 - Há teorias que se opõem a esta formulação. Ver, por exemplo, Julia Kristeva, L'engendrement de la formule in Recherches pour une sémanalyse. Paris; Du Seuil, 1969 pág. 318.

4 - Remetemos aquf aos trabalhos de V. Propp, bem como às várias utilizações de suas proposições nos textos de P. Maranda e outrós. Ver também a série Mitológicas de C. Levi-Strauss.

5 - Ver principalmente A.J. Greimas La Structure du Modèle Constitutionnel, in Du Sens, Paris; Ed. Du Seuil, 1970, pág. 136/154.

1 - Rastier, François. Les niveaux d'ambiguité des structures narratives in Langage, 7 (avril, 1968).

2 - Brecht, Bertold. O Delator In Théâtre Complet. Traduçâo para o português por um grupo do Curso e Teatro da ECA-USP em 1970.

3 - Greimas, A.J. Du sens. Ed. Du Seuil, Paris, 1970.

4- Kristeva, Julia. Recherches pour une sémanalyse. Ed. Du Seuil, Paris, 1969.

5- Kristeva, Julia — La révolution du langage poétique. Ed. Du Seuil, Paris. 1974.

6- Petôfi, J.S. - Description Grammaticale,Interpretation, Intersubjectivité. (Esquisse d'une théorie partielle du texte). Monografia apresentada no Curso Text theory, text grammar, analysis of texts. Centro Internacional de Semiôtica e Lingüfstica - Urbino, 1974.

7 - Vaina-Puscâ, Lucia - La stratégie du dialogue dramatique du point de vue de l'opposition vrai-faux, in Revue roumaine de linguistique $1973,{ }^{\circ}{ }^{\circ} 1$. 
Ambiguity, an effect of discoursives structures, generates the possibility of varied readings of the same text. Basing our idea on the work of F.Rastier (Les niveaux d'ambiguité des structures narratives), we propose to demonstrate, by means of the description of those structures, the way ambiguous effects are generated, the levels at which they are located, and thereby, reach the primary readings to be found in the text The Informer, by B. Brecht. The procedure followed was: 1 Description of the structures: (a) of the surface,comprising three hierarchical levels: actors and process, functions and syntagms; (b) of the deep structure, permitting and initial formal organization of the récit: on the paradigmatic plane the construction of the actantes, and on the syntagmatic plane the establishment of the logical relations between the sequences. II. Decription of the meaningness of the recit: (a) description of the systems of invested contents (system of social and

L'ambiguité, l'effet des structures discoursives, produit la possibilité de plusieurs lectures d'un seul texte. Tout en nous appuyant sur le travail de F. Rastier (Les niveaux d'ambiguité des strutures narratives), nous nous proposons, à travers la description de ces structures-lâ, demonstrer commentsont produit les effets ambigus, les niveaux où ils se individual values); (b) description of the formal operations carried out in the case of such contents: correlations established between the semantic struture and the semiological system. III. Construction of a model of totalized interpretation through the establishment of the correlations between the two semiological systems which permits the formulation of an interpretation of the system of social values and vice-versa, and of the positions assumed by the actantes in both systems. Thus we reach the primary readings to be found in the text in question, both arising from the manifestation of two different narrative structures, which interpreted by means of two opposite systems of values, articulate an ambiguos message oriented in two opposite directions.

The conclusions, however are provisional, the theories of the text still being formulated, do not permit systematic affirmations.

situent et atteindre ainsi, les lectures primaires inscrites dans les texte La Délation, de B. Brecht. Procedures adoptées: I (a) description des structures de surface, comprenant trois niveaux hiérarchiques: acteurs et procès, fonctions et syntagmes, (b) description des structures profondes, ce qui permet une première organization formelle du récit: sur 
le plan paradigmatique, la construction des actants; sur le plan syntagmatique, l'établissement des relations logiques entre les séquences.

II. Description du sens du récit: (a) description des systèmes de contennus investis (systèmes des valeurs sociales et systèmes des valeurs individuelles.) (b) description des opérations formelles réalisées sur les contenus relationés ci-dessus: correlations établies entre les structures sémantiques et le système sémiologique. Construction du modèle d'interprétation totalisante à travers l'établissement de la corrélation entre les deux systèmes sémiologiques, ce qui permet de formuler l'interpré- tation du système des valeurs sociales dans le système des valeurs individuelles et vice-versa, et les positions assumées par les actaiits soit dans l'un ou soit dans l'autre système. Nous avons atteint deux lectures primaires inscrites dans le texte en question, provenantes de la manifestation de deux structures narratives différentes, qui interprétées à l'aide de deux systèmes de valeurs opposées articulent un message ambigüe orienté dans deux sens opposés. Les conclusions sont, pourtant, provisoires: les théories du texte, encore en train d'étre formulées ne permettent d'en extraire des affirmations systématiques. 